\title{
Detection of Hotspots and Performance Deteriotations in PV Modules under Partial Shading Conditions Using Infrared Thermography ${ }^{\dagger}$
}

\author{
Onyinye Emmanuella Ikejiofor ${ }^{1}$, Yeboah Emmanuel Asuamah ${ }^{2}$, Howard O. Njoku ${ }^{1, *(1)}$ and \\ Samuel O. Enibe ${ }^{3}$ \\ 1 Renewable and Sustainable Energy Research Group, Department of Mechanical Engineering, \\ University of Nigeria, Nsukka 410001, Nigeria; ikejioforo@gmail.com \\ 2 Department of Energy and Environmental Engineering, University of Energy and Natural Resources, \\ Sunyani, Ghana; asuamahyeboahemmanuel@gmail.com \\ 3 Department of Mechanical Engineering, University of Nigeria, Nsukka 410001, Nigeria; \\ samuel.enibe@unn.edu.ng \\ * Correspondence: howard.njoku@unn.edu.ng or nwokoma@gmail.com; Tel.: +234-708-100-6700 \\ $+\quad$ Presented at the 7th International Electronic Conference on Sensors and Applications, 15-30 November 2020; \\ Available online: https:/ / ecsa-7.sciforum.net/.
}

Published: 15 November 2020

\begin{abstract}
Operating photovoltaic (PV) modules are frequently shaded by nearby structures, vegetation, droppings, etc., and this reduces the effective incident solar radiation received by the modules. Shading also reduces the power output of PV modules and, under certain conditions, causes the formation of hotspots. In this study, a wide variety of partial shading scenarios were investigated to evaluate their effects on the output current, voltage and efficiencies, and hotspot formation in mono-crystalline and poly-crystalline PV modules operating under the ambient conditions experienced at Nsukka, Nigeria. Sixteen shading cases were considered, including $20 \%$, $40 \%, 60 \%$ and $80 \%$ of the modules' surface areas shaded parallel to the long sides, parallel to the short sides, diagonally and randomly. Test ambient conditions, module outputs and surface thermal patterns were simultaneously monitored using a digital solarimeter, multimeter and infrared thermal imager, respectively. The outputs of the modules reduced to almost zero when as little as $40 \%$ of the module surfaces were shaded, with the reductions in performance being more severe in the mono-crystalline modules than in the poly-crystalline modules. The infrared thermography revealed the thermal patterns under the different shading conditions and showed that the random shading of the modules was the most likely to result in hotspots.
\end{abstract}

Keywords: photovoltaics; module shading; infrared thermography; PV performance

\section{Introduction}

Shading impacts negatively on the performance of solar PV systems by reducing power output and also causing permanent damage of photovoltaic (PV) modules by the formation of hotspots. It is natural to expect the decrease in power production to be proportional to the shaded module area, and this may be true for a shaded single cell. But it is hardly so at array or module levels. The need exists therefore to understand how different types of shades and their patterns affect the reliability and long term performance of PV system. In this study, the effects of partial shading conditions on the performances of monocrystalline (mono cSi) and polycrystalline (poly cSi) PV modules were compared for modules subjected to similar shading patterns and ambient conditions. 
Shading can affect a single cell of a module, an entire module or an array. Shadings have been classified into two broad groups, namely [1], (i) Objective shading, caused by conditions beyond human control which reduce the sun's overall intensity, such as cloud covering, haze, fog or heavy pollution; and (ii) subjective shading, caused objects that block incoming solar radiation and create shadows. Subjective shading is further divided into dynamic shading, caused by objects that create shadows based on the sun's angle, and static shading, caused by obstructing objects such as bird droppings, accumulated dirt, leave droppings, etc, that have come to rest on the solar module surface. Subjective shadings are preventable by proper installation, improved PV system design and periodic cleaning.

According to Bulanyi and Zhang [1], the objective shading of PV modules results in diminished current outputs even if the voltage is much less affected. Monadhil et al. [2] showed that the more the number of bypass diodes used, the less the PV module performance is diminished under fully shaded conditions. They also found out that the drop in short circuit current $\left(I_{s c}\right)$ and power of a module depends on the number and position of the shaded cells. In the study of Sathyanarayan et al. [3], there was a drastic drop in efficiency and fill factor when a significant portion of the cell was shaded during a non-uniform shading experiment. Non-uniform shading conditions were found to be capable of causing hotspots, as the non-uniform insolation on cells caused them to act as loads and produce a reverse bias behavior. Severe irreversible damage could result from hotspots caused by shades [4].

The use of infrared thermography analysis (IRT) for fault and hotspot detection in PV modules has been demonstrated in several studies [5,6], and IRT has been proposed for PV efficiency analysis since module efficiency strongly depends on module temperatures as module power output declines due to overheating. Ancuta and Cepisca [5] demonstrated the possibilities of IRT fault analysis in PV systems, showing that existing and emerging hotspots could be detected in the early stages of module installation when a low temperature difference may exist between faulty areas and the panel itself.

The above studies notwithstanding, the present study was undertaken to comparatively investigate the application IRT to a broad range of shading scenarios that are yet to be investigated in existing studies. Both monocrystalline and polycrystalline modules were studied, and shades that aligned with module width and length, and randomly occurring shades were investigated.

\section{Materials and Methods}

Polycrystalline and monocrystalline PV modules in pairs were simultaneously tested under the outdoor conditions prevailing at the University of Nigeria, Nsukka $\left(6.84^{\circ} \mathrm{N}, 7.37^{\circ} \mathrm{E}\right)$ within the months of October and December 2018. During the tests, the modules were oriented facing south (as the rule of thumb for locations in the northern hemisphere specifies) and inclined $22^{\circ}$ to the horizontal for normal incidence of incoming solar radiation on the module surfaces. The specification of the modules are given in Table 1.

Table 1. Specification of test PV modules.

\begin{tabular}{ccc}
\hline Specification & Monocrystalline & Polycrystalline \\
\hline Manufacturer & Rubitec Solar & Rubitec Solar \\
Model Type & HU 40 & PV 40P \\
Quantity & 2 & 2 \\
maximum Power, $P_{\max }(\mathrm{W})$ & $40 \mathrm{~W}( \pm 5 \%)$ & $40 \mathrm{~W}( \pm 3 \%)$ \\
Current at $P_{\max }, I_{\max }(\mathrm{A})$ & 2.22 & 2.25 \\
Voltage at $P_{\max }, V_{\max }(\mathrm{V})$ & 18.0 & 17.8 \\
Short circuit current, $I_{S C}(\mathrm{~A})$ & 2.43 & 2.39 \\
$\mathrm{~V}$ & 22.1 & 21.7 \\
No. of cells & 68 & 36 \\
\hline
\end{tabular}


The modules were mounted on a stand during the tests (Figure 1a) as its surface temperature was measured using a K-type thermocouple connected to data logger; the prevailing insolation was measured with the TES 1333R Data logging solarimeter (Figure 1b); thermal profiles of the backside of the PV modules were obtained with a mobile phone-connected SEEK thermal imager (Figure 1c); module output voltage and currents were measured with a UNI-T UT61C digital multimeter (Figure 1d), while the prevailing wind speeds during the tests were measured with an anemometer. The measurements were recorded in one minute intervals and each test session lasted 20-30 min. The experiments were repeated twice to compare the readings taken.

The module performances were characterized by their efficiencies $\eta$ and maximum power output $P_{m p}(\mathrm{~W})$, which were determined as follows:

$$
\begin{gathered}
\eta=V_{m p} I_{m p} /(I A) \\
P_{m p}=V_{m p} I_{m p}
\end{gathered}
$$

where $V_{m p}=$ voltage at maximum power $(\mathrm{V}), I_{m p}=$ current at maximum power $(\mathrm{A}), I=$ insolation $\left(\mathrm{W} / \mathrm{m}^{2}\right)$, $A=$ module surface area $\left(\mathrm{m}^{2}\right)$ and $V_{o c}=$ module open circuit voltage $(\mathrm{V})$.

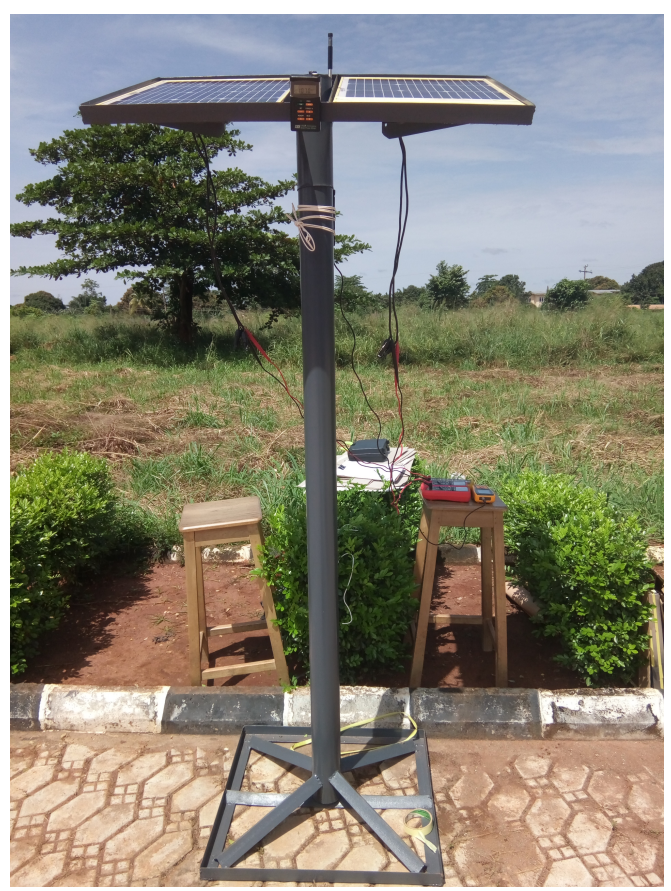

(a)

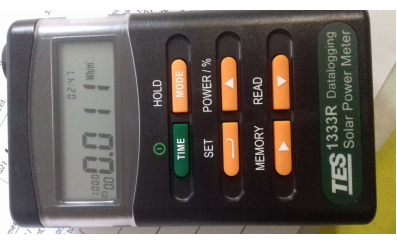

(b)

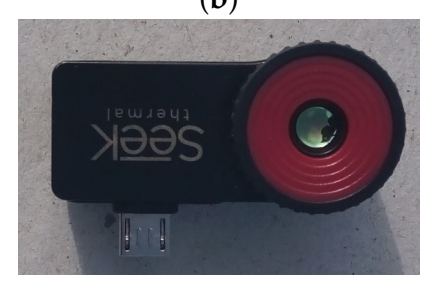

(c)

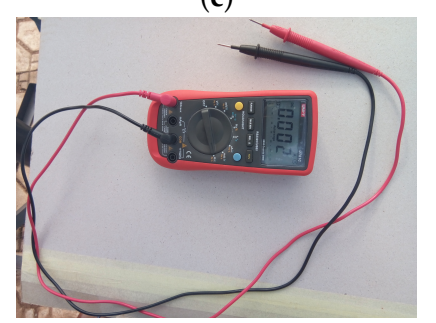

(d)

Figure 1. Experimental setup: (a) test stand, (b) solarimeter, (c) thermal imager, (d) digital multimeter.

The modules were subjected to different partial shading patterns, with one module serving as the control while the other identical one was the experimental module. Cardboard sheets, $3 \mathrm{~mm}$ thick, were cut into suitable shapes to achieve the desired shading patterns that were investigated. The experimental modules' surface areas were shaded parallel to the module lengths and widths, diagonally and randomly, to achieve between $20 \%$ and $80 \%$ shading of the module surfaces. 


\section{Results and Discussion}

Figure 2a shows the power outputs and efficiencies of the mono cSi modules, as well as irradiance and ambient temperatures, when $20 \%$ of the test module was shaded parallel to its width. The power output of the modules generally followed the pattern of irradiance. Under an irradiance of $1151 \mathrm{~W} / \mathrm{m}^{2}$, the maximum power produced by the shaded module was $4.7 \mathrm{~W}$ compared to a $32 \mathrm{~W}$ output by the unshaded module. Furthermore, the unshaded module's peak efficiency was $\sim 16.89 \%$ whereas peak efficiency for the shaded module was $\sim 2.47 \%$. Thus a $20 \%$ reduction in the irradiation of the module surface (due to the shading) led to an $85.3 \%$ percentage drop in its efficiency.

The results for the poly cSi PV modules are shown in Figure 2b. The modules' power output also followed the pattern of irradiance, and attained peak values of $8.69 \mathrm{~W}$ and $42.8 \mathrm{~W}$ in the shaded and unshaded modules, respectively, at an irradiance of $866.2 \mathrm{~W} / \mathrm{m}^{2}$. As a result of the shading, the peak efficiency dropped by $79.5 \%$ (from $22.94 \%$ in the unshaded module to $4.72 \%$ in the shaded module). These drastic efficiency declines in both mono and poly cSi modules affirms that module performance reductions are not linear with reductions in irradiation.

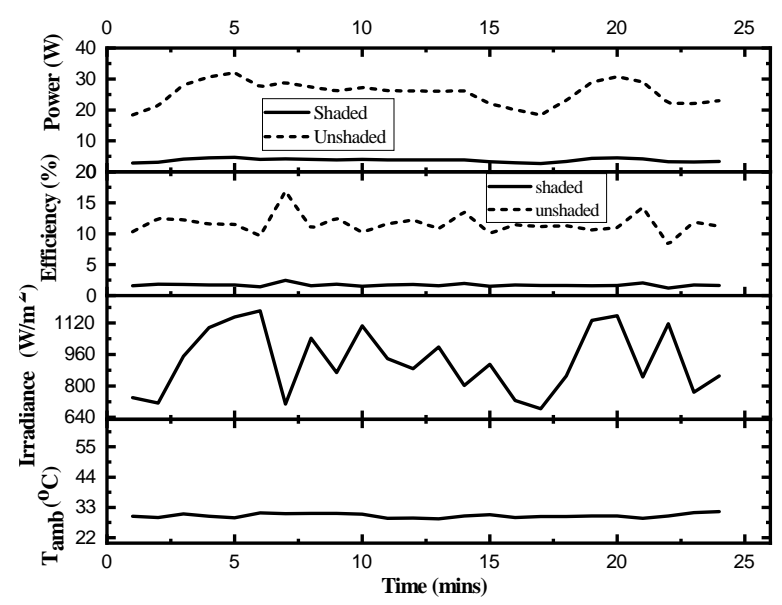

(a) Impact of $20 \%$ horizontal shading on the mono cSi PV module

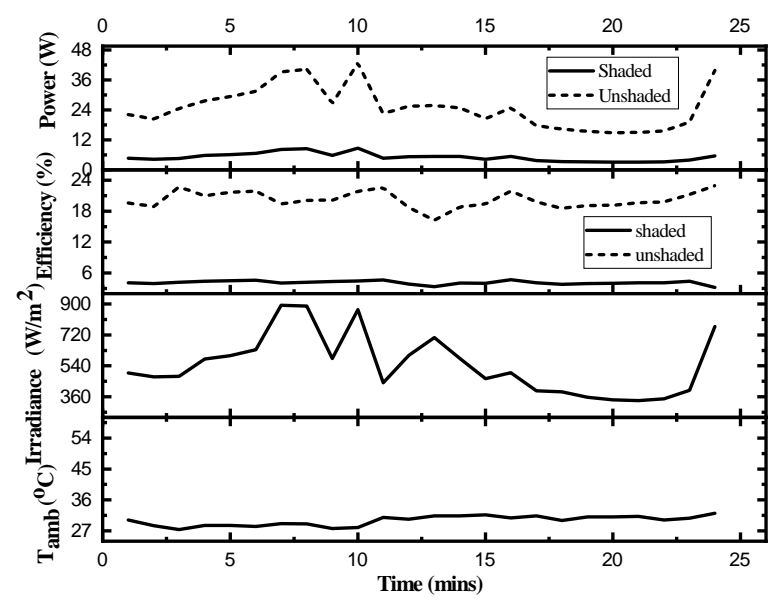

(b) Impact of $20 \%$ horizontal shading on poly cSi PV module

Figure 2. Power outputs and efficiencies of (a) mono and (b) poly cSi modules for $20 \%$ shading along the width of the test modlules. 
These power output declines are compared in Figure 3 for the different shading patterns and shading values. The reductions in power output due to shading were generally less in the monocrytalline module except when shading was along the length of the modules (Figure $3 b$ ). At $20 \%$ shading, the power outputs of both module types declined significantly, except when the shading was along the width of the modules. Beyond 20\% shading, the modules had virtually no power output, except when shading was along the module widths, for which power output drops were less (Figure 3d).

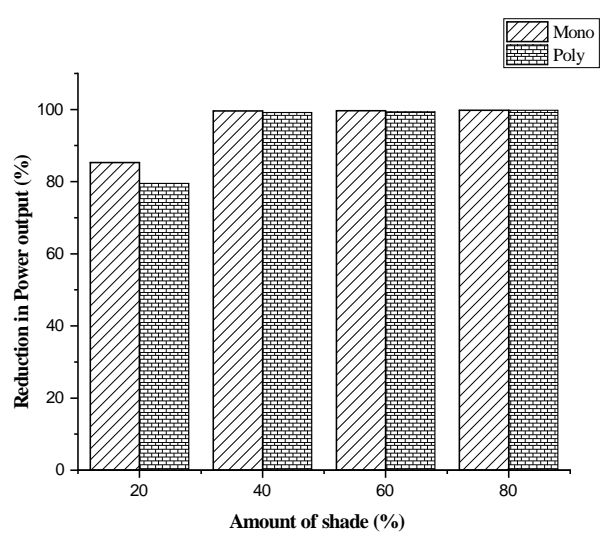

(a)

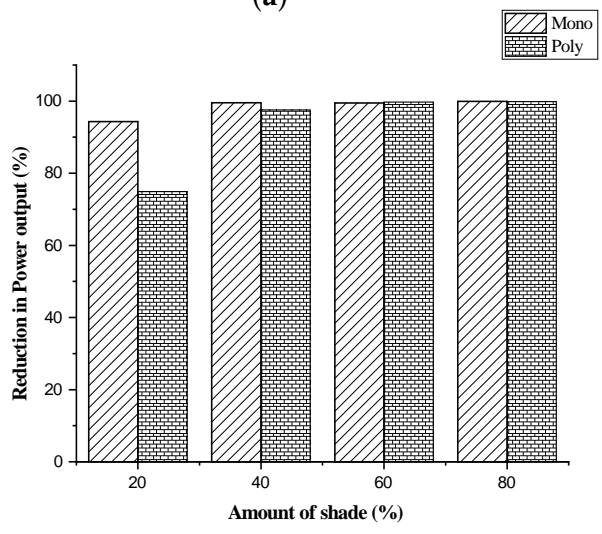

(c)

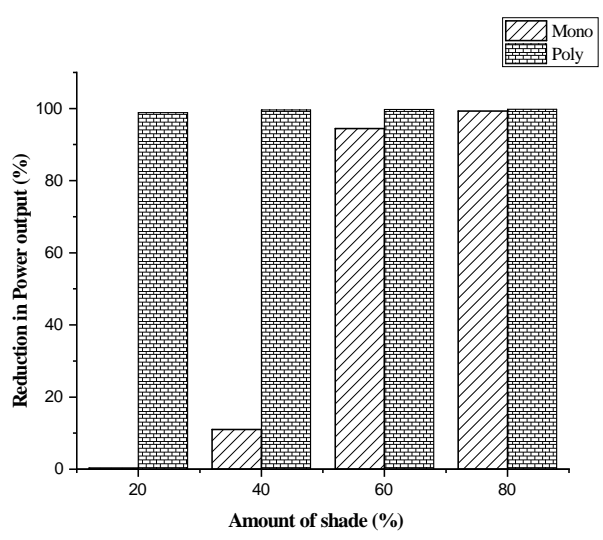

(b)

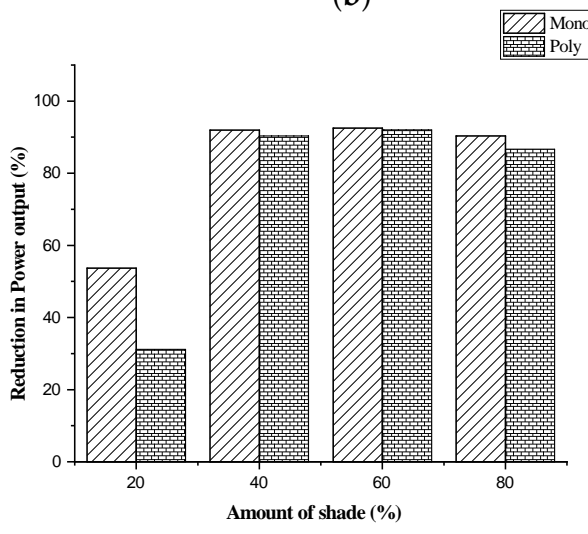

(d)

Figure 3. Percentage drop in power output for the mono and polycrystalline modules. (a) Horizontal Shading; (b) Vertical Shading; (c) Diagonal Shading; (d) Horizontal Shading.

Figure $4 \mathrm{a}, \mathrm{b}$ are the thermal and normal images, respectively, when the mono cSi module was shaded $20 \%$ along its width. The thermal image shows both modules to be free of hotspots but reveals a surface temperature drop $\left(\sim 8^{\circ} \mathrm{C}\right)$ caused by the shading in the shaded module (lower right of Figure $4 \mathrm{a})$. Such abrupt temperature changes could affect module integrity due to accompanying thermal stresses. The images obtained when the poly cSi module was shaded $20 \%$ along its width are shown in Figure 5a,b, respectively. The thermal image shows hotspots in the control (unshaded) module, suggesting the presence of defects, while the shaded module, which had no hotspots again experienced a surface temperature drop $\left(>10^{\circ} \mathrm{C}\right)($ lower right of Figure $5 \mathrm{a})$ due to the shading. 


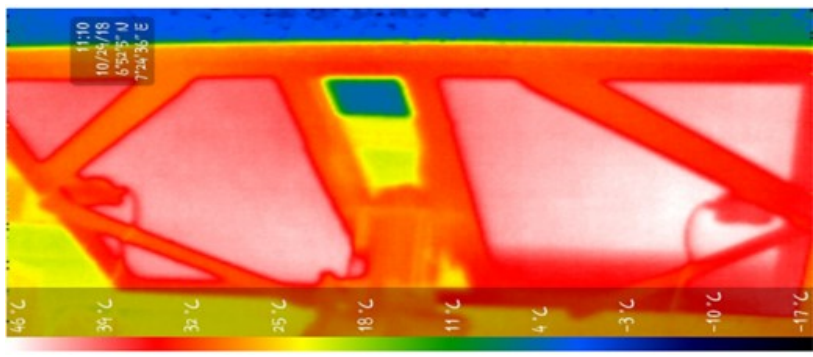

(a)

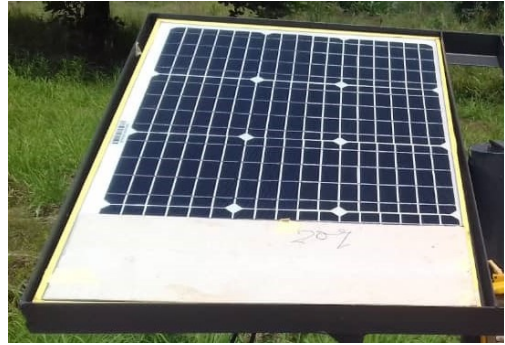

(b)

Figure 4. 20\% shading of mono cSi PV module along module width. (a) IR image of unshaded and shaded modules; (b) Normal image of shaded modules.

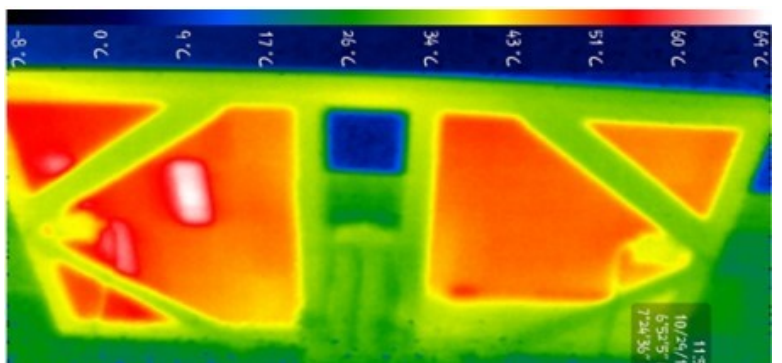

(a)

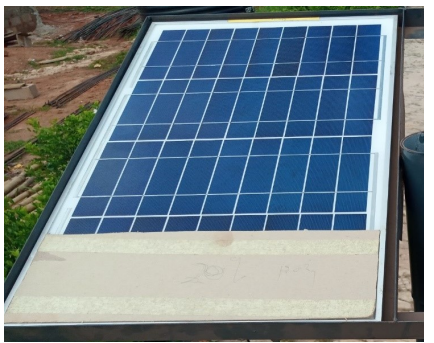

(b)

Figure 5. 20\% shading of $40 \mathrm{~W}$ poly cSi PV module along module width. (a) IR image of unshaded and shaded modules; (b) Normal image (shaded module).

Similar images were obtained for mono cSi modules shaded along their lengths (Figure 6a) and randomly (Figure 6b), and for similarly shaded poly cSi modules (Figure 7a,b, respectively). In all cases, the thermal images showed that the shaded portions of the modules had lower temperatures than the unshaded portions. Futhermore, the thermal images clearly revealed hotspots in the modules (Figures $6 \mathrm{a}$ (left), $6 \mathrm{~b}$ (left), $7 \mathrm{a}$ (left) and $7 \mathrm{~b}$ (right), resulting either from inherent flaws or damage during use. The images also showed hotspots due to shading (Figures $6 \mathrm{~b}$ (right) and $7 \mathrm{~b}$ (left)), and these occurred when the modules were shaded randomly. The hotspot temperatures were between $44^{\circ} \mathrm{C}$ and $55^{\circ} \mathrm{C}$, much higher than the recorded mean module temperatures.

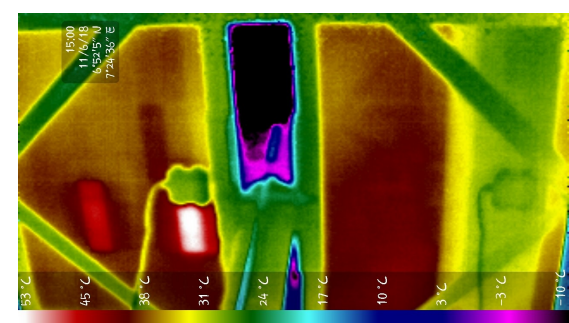

(a)

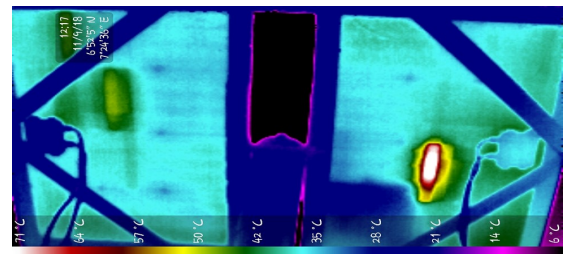

(b)

Figure 6. IR images of mono cSi modules for (a) 60\% shading along its length and (b) random shading.

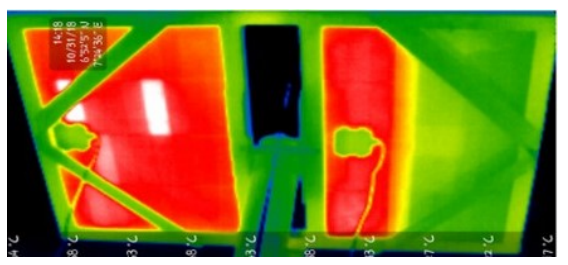

(a)

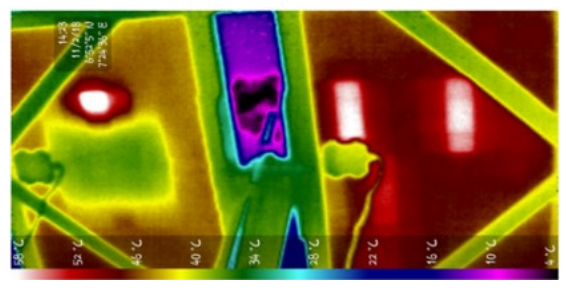

(b)

Figure 7. IR images of poly cSi modules for (a) $60 \%$ shading along its length and (b) random shading. 


\section{Conclusions}

This study investigated reductions in power output of mono-cSi and poly-cSi PV modules under different partial shading scenarios and attendant hotspots formations. Power outputs reduced to almost zero when only about $40 \%$ of module surfaces were shaded, and the losses were more severe in the mono-cSi modules. Module damage, indicated by hotspots, which were more likely caused by random shades, were clearly revealed by the IRT analysis of the modules.

Author Contributions: Conceptualization, H.O.N.; methodology, H.O.N. and O.E.I.; software, O.E.I.; validation, O.E.I.; formal analysis, H.O.N. and O.E.I.; investigation, O.E.I. and Y.E.A.; resources, H.O.N. and O.E.I.; data curation, O.E.I.; writing-original draft preparation, O.E.I. and S.O.E.; writing-review and editing, H.O.N. and S.O.E.; supervision, S.O.E. and H.O.N.; project administration, H.O.N.; funding acquisition, O.E.I. All authors have read and agreed to the published version of the manuscript.

Funding: This research received funding from the African-German Network of Excellence in Science (AGNES) 2018 mobility grant.

Conflicts of Interest: The authors declare no conflict of interest.

\section{References}

1. Bulanyi, P.; Zhang, R. Shading analysis \& improvement for distributed residential grid-connected photovoltaics systems. In Proceedings of the 52nd Annual Conference of the Australian Solar Council, Melbourne, Australia, 8-9 May 2014.

2. Al-chaderchi, M.; Sopain, K.; Alghoul, M.; Salameh, T. Experimental study of the effect of fully shading on the Solar PV module performance. E3S Web Conf. 2017, 23, 01001.

3. Sathyanarayana, P.; Ballal, R.; Sagar, P.L.; Kumar, G. Effect of shading on the performance of solar PV panel. Energy Power 2015, 5, 1-4.

4. Alonso-Garcia, M.; Ruiz, J.; Chenlo, F. Experimental study of mismatch and shading effects in the I-V characteristic of a photovoltaic module. Solar Energy Mater. Solar Cells 2006, 90, 329-340.

5. Ancuta, F.; Cepisca, C. Fault analysis possibilities for PV panels. In Proceedings of the 2011 3rd International Youth Conference on Energetics (IYCE), Leiria, Portugal, 7-9 July 2011; pp. 1-5.

6. Solheim, H.J.; Fjær, H.G.; Sørheim, E.A.; Foss, S.E. Measurement and simulation of hot spots in solar cells. Energy Procedia 2013, 38, 183-189.

Publisher's Notes: MDPI stays neutral with regard to jurisdictional claims in published maps and institutional affiliations.

(C) 2020 by the authors. Licensee MDPI, Basel, Switzerland. This article is an open access article distributed under the terms and conditions of the Creative Commons Attribution (CC BY) license (http:/ / creativecommons.org/licenses/by/4.0/). 